\title{
Role Demands and Work Life Balance among Women Lecturers in Sri Lankan State Universities
}

\author{
Welmilla I. \\ Department of Human Resource Management, University of Kelaniya \\ iwelmilla@kln.ac.lk
}

\begin{abstract}
The main purpose of this study is to examine the relationship between role demands of work, family and work life balance. Also, this study tried to explore the factors that influence the supportive work life balance of the women academic staff in university. In quantitative phase of the study, a questionnaire survey was used to gather data from 265 women lecturers in state universities of Sri Lanka. Twenty in -depth interviews were conducted with women lecturers in same universities as gathering qualitative data. Finding of structural equation modeling indeed indicate that the significant negative relationship between role demands and work life balance, it fills a gap in the literature by validating the associations between role demands and work life balance dimensions. The qualitative data were analyzed via thematic exploratory analysis, which suggest that supportive factors for work life balance, such as workplace flexibility, avoiding role interference, correct prioritization, good working environment and personal factors against the role demands, that will be useful to Sri Lankan women in the academic profession to avoid their imbalance of work and family life and it also sends an important message to individuals to encourage work and family satisfaction.
\end{abstract}

Keywords: Family Demand, Women Academic Staff, Work Demand, Work Life Balance

Copyright: (C) 2018 Welmilla I. This is an open access article distributed under the Creative Commons Attribution License, which permits unrestricted use, distribution, and reproduction in any medium, provided the original work is properly cited.

Correspondence: iwelmilla@kln.ac.lk

ORCID of authors: Indumathi Welmilla - https://orcid.org/0000-0003-1705-0779

DOI: http://10.4038/kjm.v7i2.7577 


\section{Introduction}

Universities are the largest "knowledgebased" institution in the region; hence they are urged by the industry and policymakers to transform their traditional roles of teaching and research by adding an additional pivotal role in economic regional development (Diaco, Hughes, \& McKelvey, 2012). This means that university academic staffs are expected to aid economic regeneration by disseminating their knowledge and expertise economic growth. However, university academic staffs do not only serve to undergraduates/ students, but also as a contributor to economic development. Not only that, they have big demands in their family or personal lives as well as professional lives. Therefore, university academic staffs face greater challenges in achieving a balance between professional and personal life due to the have demands of work and family roles.

Academic status is a very special position, it is needed several belongings such as intelligence, knowledge, experience for the field and skills. However, when comparing the men, women family life freedom is very fewer than the men (Flores \& Day, 2006). According to Goyal and Arora (2012), most women employees are under pressure to balance the priorities of family and work. Punia and Kamboj (2013) pointed out that academic employees currently face great challenges in achieving a balance between their professional life and personal life. However, nowadays the education sector is required to take on greater challenges in achieving the global demands and expectations of the new world. The academic excellence is to ensure the competitiveness of the nation. Likewise, in the context of Sri Lanka, the higher education sector has been upgrading continuously. During the last two decades, it has been increased the quality of university education (Chandra, 2017). A number of World Bank projects were introduced by Ministry of Higher Education and University Grant Commission (UGC) to the state universities to improve the quality of teaching, learning and assessment methods for undergraduate degree programs. (examples, IRQUE (Improving Relevance and Quality of University Education) Project, QAA (Quality Assurance Agency), Distance Education Modernization Project (DEMP), Higher Education for Twenty-first Century (HETC)). However, to achieve the unique quality of above education system in Sri Lanka, the role of teaching staff should be continuously enhanced as they are the main pillars in the sector. In Sri Lankan university education system, lecturers have different responsibilities such as teaching, administrative tasks, involving education reforms, evaluating students performs, attending staff development programs, and do the research for developing the country economy. Therefore, all lecturers of the university system have great job demand to carry out their duties diligently.

Most studies find that there is an imbalance in the work and personal lives of women in the teaching profession (Goyal \& Arora 2012; Punia \& Kamboj 2013), therefore making it necessary that academics find a solution to this problem.

\section{Problem Statement}

Most research on work life balance (WLB) experiences has been carried out in Western contexts (Cohen \& Kirchmeyer 2005; Poelmans et al., 2003; Roehling, Jarvis, \& Swope, 2005). Furthermore, reviewing the literature, it was identified that there was a dearth of research studies have been conducted on role demands (RDs) and WLB experiences among the academic women in the Sri Lankan context. Thus, there is a research gap on this regard. Therefore, the current study is trying to fill this gap which is identifying the 
relationship between of RDs and WLB experience of women academic staff in Sri Lanka. Furthermore, this study was focused on to identify the different factors that contribute to the supportive WLB behavior among the women in an academic profession in Sri Lanka.

\section{Research Questions}

Given to the shortcomings in the literature this study addresses the following research questions:

i. What are the relationships between RDs and WLB of women in an academic profession in Sri Lanka?

ii. What are factors that contribute to the supportive WLB behavior among the women in an academic profession in Sri Lanka.

\section{Objective of the Study}

The current study aims to achieve the following objectives:

i. To determine the relationship between RDs (work and family) and WLB among women in the academic profession.

ii. To identify the factors which contribute to supportive WLB behavior among women in the academic profession in Sri Lanka.

\section{Literature Review}

\section{Work life balance}

Many research articles have been conducted to understand of the WLB of the different job categories (Carlson, Kacmar, Grzywacz, Tepper, \& Whitten, 2013; Clark, 2001; Hill, 2005). According to Carlson et al. (2013) WLB as a composition of work satisfaction and family satisfaction. Clark (2001) defined work life balance as "satisfaction and good functioning at work and at home with a minimum of role conflict" (p.349). These definitions include, that WLB is how people play a successful role in both domains of work and family with minimum role conflict. Based on Clark (2001) definition WFB includes five dimensions such as work satisfaction, family satisfaction, work functioning, family functioning, and role conflict.

As well, Higgins, Duxbury, and johnson (2000) defined WLB as a "perceptual phenomenon characterized by a sense of having achieved a satisfactory resolution of the multiple demands of work and family domains" (p.19). Furthermore, Hill (2005) interpreted WLB is referring how an individual simultaneously balances the temporal, emotional, and behavioral demands of both paid work and non- paid work activities. Also, researchers such as Chan, (2008) and Blunsdon, Blyton, Reed, and Dastmalchian, (2006) supported Hill's (2005) definition, presenting same ideas of their definitions. They described WLB as the successful integration of an individual's life and work, also elaborated on this expression by looking at psychological factors. Consequently, it was noted that WLB is about attaining a satisfying quality of life, overall satisfaction with less stress.

Greenblatt (2002) defined WLB as "the absence of unacceptable levels of conflict between work and non- work demands" (p.179). Thus, when demands from the work and life domains are mutually contradictable, conflict may arise. It is important to note that prior studies have defined that WLB as an aspect of role conflict, because researchers have supposed that the absence of work - life conflict or the existence of work life enrichment is equivalent to WLB (Frone, 2003). As well, Frone (2003) defined WLB as "low levels of inter role conflict and high levels of inter-role facilitation" (p.145). His 
views of WFB as a state wherein an individual's work and family lives experience little conflict while enjoying substantial facilities. Recently, Allen, Johnson, Kiburz, and Shockley (2013) stated that balancing work and life roles of individuals' feel strain and conflict. Furthermore, they explore the conflicts that individuals have when work roles interfere with life roles and when life roles interfere with work roles. Therefore, work family conflict can be identified as work interfering to family and family interfering to work.

\section{Role demand of work}

Definitions of work demand (WD) and family demand (FD) have been too narrow. Boyar, Carr, Mosley, and Carson (2007) defined demand as "a global perception of the level and intensity of responsibility within the work or family domain" (p.103). Voydanoff (2005) demonstrated two types of WD; time- based and strain- based. Moreover, time- based WD includes long working hours, overtime, and organizational time expectation while strain- based work demand may include work overload, work pressure, and work distress. Therefore, WDs can be measured through objective characteristics as well as subjectively experienced by the employees (Boyar et al., 2007). Amongst widely cited, several WDs were found to be associated to higher levels of work life conflict and lower level of WLB (Voydanoff, 2005; Batt \& Valcour, 2003; Valcour, 2007; Major, Klein, \& Ehrhart, 2002). These WDs were included, long working hours, hours worked, work overload, and work pressure and work distress. Also, Valcour (2007) has developed his own multi-item scale and used it in his empirical study which was revealed high level of work life conflict are influenced to less satisfied with their ability to balance their work and family responsibilities. Furthermore, Valcour (2007) proved satisfaction with WLB is negatively related with working hours. Moreover,
Aycan (2008) investigated a strong positive relationship between work life conflict and work overload. Based on the evidence line with past research, it was proved that role of WD decreases and WLB is increased. In the particular that, the following hypothesis was proposed.

$\mathrm{H}_{1}$ : WD is negatively associated with WLB of women in academic staff.

\section{Role demand of family}

Noor (2004) has proposed that women are the principal responsible person for the home yet, even if she is working. However, doing these responsibilities for family, it facilitates WLB and helps reduce work family conflict (Elisabeth, 2003). Huang, Hammer, Neal, and Perrin (2004) found that work family conflict has a positive correlation with the family demand (FD) for child care. This means WLB of individuals negatively correlated with FDs. Family satisfaction is the individual attitude or positive feeling towards family life (Edura, Mohamad, Azura, \& Izhairi, 2012). Samsinar, Murali, and zhairi (2010) empirically proved that the overall satisfaction with family life has a significant positive relationship with quality of non - work (family) life. Likewise, they reported, that the quality of family life is gaining from having personal time and spending time with family members. Consequently, spending time with family is significantly influence, to the FDs dimensions such as child care, household chores and, perceived family demand. Considering the above facts researcher hypothesized that, there is a negative relationship between WLB and FDs. Based on the evidence line with past research, it was proved that the role of FD increase WLB is decreased. In the particular that, the following hypothesis was proposed.

$\mathrm{H}_{2}$ : FD is negatively associated with WLB of women academic staff 


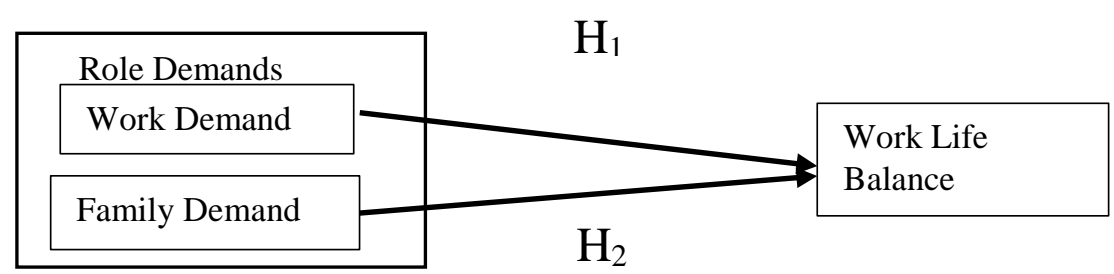

Figure 1: Conceptual Framework for the Study

Source: Author's Design

Based on the empirical evidences the conceptual framework (Figure 1) was developed. WD and FD are considered as the exogenous constructs while WLB is considered as endogenous construct.

\section{Research Methodology}

\section{Sample, Data Collection and Measure- ment}

This study is the first of its kind to deal with the higher education sector and it will be mixed method design which combined quantitative and qualitative methods applied sequentially. In the study, the first objective is to determine the relationship between RDs and WLB experiences of women academic staff in Sri Lankan universities, and the second objective is to identify the factors that contribute the supportive WLB behavior among the women in an academic profession in Sri Lanka.

To fulfill the first objective two hypotheses were advanced. The quantitative approach is used to verify the hypotheses. A self-administered questionnaire was used to gather data on WLB and work- family demands. The population element has known, the researcher used one of the probabilistic sampling technique, called stratified random sampling method. Questionnaires were distributed to 300 lecturers in state universities. Out of 300 questionnaires distributed, 265 questionnaires, which constitute of 88.3 percent response rate, were returned and usable for analysis. In the study, the questionnaire adapted from original sources and some modifications were made to suit the context of the study.

A total of 23 items with the five-point Likert scale were used to measure all variables under study. Fifteen items were adopted from work interference with personal life scale developed by FisherMcCauley Stanton, Jolton, and Gavin (2003) to measure WLB as the endogenous latent construct. Sample items for this construct are "My personal life suffers because of work" and "I neglected my personal needs because of work".

Two exogenous latent constructs of WD and FD were measured by using 4 items scales for each, which had been previously used by Boyar et al. (2007). Sample items for work demand construct are "I feel like I have a lot of work demands" and "I feel like I have a lot to do at work" and sample items for family demand construct are "I have to struggle when managing family related activities" and "My family requires all of my attention".

To achieve the second objective of this study that was to identify the factors that contribute the supportive WLB behavior among the women in an academic profession in Sri Lanka, the qualitative approach is used. Semi-structured face - to- face interviews were conducted to gather data. Twenty women lecturers selected from state universities by using purposive sampling technique as the sample. Respondents were asked about their demographic 
and WLB experiences. Consent forms were presented to the respondent at the start of each interview which stated the purpose of the study.

\section{Data Analysis}

Quantitative data were analyzed using SPSS 21.0 and AMOS 22.0 software. As the first step of the quantitative analysis, the measurement model was examined with confirmatory factor analysis (CFA) using all variables (WD, FD and WLB) to determine the relationship between latent constructs and measurement items. It also provided the reliability and validity of the construct. Then the structural model assessed to test the hypotheses that reflect the relationships of RDs and WLB. The model fit was determined through goodness- of -fit indices.

The purpose of analyzing qualitative data a thematic analysis approach was adopted. Some interviews were recorded and some were written manually. Transcripts were also prepared manually and checked each transcript for accuracy and completed sections of all interviews. For each interview, a detailed protocol was written summarizing the main statements of the participants. A comparison of all interview transcripts was used to identify common themes and to classify statements.

\section{Results}

\section{Measurement model}

In this study there were two exogenous constructs; WD and FD and the endogenous construct was the WLB. The data were prepared and screened before performing the analysis. Descriptive statistics analysis was performed as a pretest of data cleaning. Exploratory factor analysis (EFA) was used to decide whether the data at hand suits the underlying constructs, thereby ascertaining their appropriateness. Ensuring validity and logical solution, multivariate assumptions were tested for the data set. The measurement model was assessed with the test of item's loading and reliability. Factor loading for all items was above 0.6, were considered acceptable reliability. For Bartlett's test of sphericity also were significant with p-value 0 and KMO statistics were above 0.6 for all constructs $\quad(\mathrm{WLB}=0.87, \mathrm{WD}=0.81$, $\mathrm{FD}=.77)$. KMO also supports factor analysis. In addition to EFA, CFA was utilized to test the validity and reliability of the measurement model and assess modify the proposed research model. Figure 1 depicts the modified full measurement model which was incorporated all latent constructs indicated by respective items pertaining to each scale.

Internal consistency reliability was confirmed by examining the composite reliability (CR) coefficients and Cronbach's alpha coefficients of each construct (Henseler, Ringle, \& Sinkovics, 2009). All CR and Cronbach's alpha values were above 0.7 suggested that internal consistency reliability for each construct were achieved. In addition to that, the values of average variance extracted (AVE) were also examined to determine the convergent validity of WLB, WD, and FD. The results showed that the values of AVE for all constructs were above 0.5 , suggest adequate convergent validity (Hair, Black, Babin, \& Anderson, 2010). Table 1 shows the summarized results of assessing the measurement model.

\section{Assessment of structural model}

After achieving the satisfactory fit of the measurement model, a structural model was tested. Purpose of the structural model is to test the underlying hypotheses. In this study, two direct hypotheses were advanced to test the relationship between RDs and WLB. Proposed structural model shown in Figure 2, the underline variables are classified into exogenous variables and endogenous variable. In the Structural Equation Model (SEM) method, ensuring the model fit is very important. The three 
essential measurements were taken into account for verifying the model fit: Chisquare (CMIN/DF), Goodness of Fit Indices (GFI) and Root Mean Square Error of Approximation (RMSEA). Model fit indicators exhibited a good fit, as CMIN/DF less than 3, GFI is greater than 0.80 , and RMSEA is less than 0.8 (Hair et al., 2010) between the data and conceptualization model. The model fit statistics in table 2 shows the acceptability of the structural model.

Table 1: Results of Assessing the Measurement Model

\begin{tabular}{|c|c|c|c|c|c|c|}
\hline Construct & Items & $\begin{array}{l}\text { Item load- } \\
\text { ing }\end{array}$ & $\begin{array}{l}\text { Item relia- } \\
\text { bility }\end{array}$ & $\begin{array}{l}\text { Cronbach's } \\
\text { Alpha }\end{array}$ & $\mathrm{CR}$ & AVE \\
\hline \multirow{15}{*}{ WLB } & WLB1 & 0.553 & 0.554 & \multirow{15}{*}{0.786} & \multirow[t]{15}{*}{0.708} & \multirow[t]{15}{*}{0.603} \\
\hline & WLB2 & 0.824 & 0.767 & & & \\
\hline & WLB3 & 0.901 & 0.832 & & & \\
\hline & WLB4 & 0.921 & 0.878 & & & \\
\hline & WLB5 & 0.916 & 0.833 & & & \\
\hline & WLB6 & 0.926 & 0.879 & & & \\
\hline & WLB7 & 0.951 & 0.888 & & & \\
\hline & WLB8 & 0.939 & 0.888 & & & \\
\hline & WLB9 & 0.827 & 0.855 & & & \\
\hline & WLB10 & 0.893 & 0.847 & & & \\
\hline & WLB11 & 0.933 & 0.843 & & & \\
\hline & WLB12 & 0.533 & 0.621 & & & \\
\hline & WLB13 & 0.541 & 0.632 & & & \\
\hline & WLB14 & 0.558 & 0.631 & & & \\
\hline & WLB15 & 0.547 & 0.632 & & & \\
\hline \multirow[t]{4}{*}{ WD } & WD1 & 0.951 & 0.867 & \multirow[t]{4}{*}{0.884} & \multirow[t]{4}{*}{0.878} & \multirow[t]{4}{*}{0.698} \\
\hline & WD2 & 0.950 & 0.866 & & & \\
\hline & WD3 & 0.930 & 0.853 & & & \\
\hline & WD4 & 0.908 & 0.789 & & & \\
\hline \multirow[t]{4}{*}{ FD } & FD1 & 0.925 & 0.801 & \multirow[t]{4}{*}{0.787} & \multirow[t]{4}{*}{0.797} & \multirow[t]{4}{*}{0.651} \\
\hline & FD2 & 0.954 & 0.868 & & & \\
\hline & FD3 & 0.948 & 0.865 & & & \\
\hline & FD4 & 0.795 & 0.643 & & & \\
\hline
\end{tabular}

Source: Data analysis results, 2018 
Table 2: Model Fit Statistics of the Structural Equation Model

\begin{tabular}{|l|l|l|l|}
\hline Fit Indications & CMIN/DF & GFI & RMSEA \\
\hline Value & 2.24 & 0.91 & 0.71 \\
\hline
\end{tabular}

Source: Adapted from data analysis results, 2018

Table 3: Hypotheses testing: AMOS output extract

\begin{tabular}{|l|l|l|l|l|l|l|}
\hline Path & $\begin{array}{l}\text { Hypothe- } \\
\text { sized Di- } \\
\text { rection }\end{array}$ & $\begin{array}{l}\beta \text { (path co- } \\
\text { efficient) }\end{array}$ & SE & $\begin{array}{l}\text { Critical } \\
\text { Ratio }\end{array}$ & P value & Supported \\
\hline H1 & Negative & -0.654 & 0.049 & -12.368 & 0.000 & Yes \\
\hline H2 & Negative & -0.629 & 0.050 & -11.868 & 0.000 & Yes \\
\hline
\end{tabular}

Sources: Adapted from data analysis results, 2018

\section{Hypotheses testing}

Hypotheses were tested through the SEM using AMOS 2. The path that connects work demand to WLB yields a significant coefficient value of $-0.249(\mathrm{SE}=0.049$, $\mathrm{CR}=-12.368, \mathrm{P}=0.000$ ) Hence, a significant negative path coefficient is suggested that WD is negatively associated WLB, as predicted, thereby confirming $\mathrm{H}_{1}$. In other words, the result of standardized regression weights output is providing support for $\mathrm{H}_{1}$. The path coefficient $(\beta)$ value that is produced family demand and WLB is 0.076. This is significant results
$(\mathrm{SE}=0.050, \mathrm{CR}=-11.868, \mathrm{P}=0.000)$. In effect, this path is also considered that FD is significantly associated with the degree of WLB at a significance level of 0.001, which provides support for hypothesis 2 . The standardized regression weights of the output and result of hypotheses testing providing support for hypotheses $\mathrm{H}_{1}$ and $\mathrm{H}_{2}$ is presented in table 3 . Moreover, the result revealed WD and FD jointly explain 10 percent of the variance in WLB. 
To fulfill the second objective; to identify the factors that contribute the supportive work life balance behavior among the women in an academic profession in Sri Lanka, the thematic analysis was applied. In line with the analysis process, individual transcripts were read and re-read a number of times, following by a writing process as the first step of an analysis procedure. As part of the writing process, meaning units were grouped together and eventually organized into themes and subthemes.

Through the in-depth interviews' data analysis, aimed to identify factors that contribute the supportive WLB from the 21 themes that were initially extracted during the open coding phase, five key themes were discovered as the result of using thematic analysis. These themes were Flexibility, Personal factors, Role interference, Prioritization of roles, and Work Environment.

\section{Flexibility}

All respondents confirmed that flexibility of work schedule and working hour directly influence to reduce their work life imbalance. Furthermore, they emphasized flexible work schedules can contribute to less work family conflict in households. As well as it contributes to employee loyalty and work satisfaction. Some interviewees responded, "Flexible work schedule and working hours highly beneficial for balancing my dual roles, it allows me to take and pick up my children from school daily, it also allowed me to care my elder mother, I do my heavy workload week ends, evenings".

\section{Role Interference}

Two main interference types have been described by the respondents; family interference within work life and work interference within family life. More respondents experienced both of these interfer- ences intended to decrease WLB. Concerning the respondents' feeling about their professional life interference within family life, the reason is the high level demanding of the work role. Their argument was as the teaching profession that their work roles were overloaded, then conflict arises because of hindering family activities and requiring more commitment toward work responsibility. Some of the responses quoted by; "According to nature of my profession it is very demanding, need more hours, during my working hours I can't complete all my job duties, When I am in home, I do my job duties, I can't work for home. I believe that with three kids and no help at home very big problem for me." On the other hand, some respondents' do not perceive that their family life responsibilities interfere with their work life when they succeed in achieving WLB.

\section{Prioritization of Roles}

The respondents' idea was that someone able to priorities their roles and separate their various roles he/ she can achieve a greater balance between their professional and personal lives regardless of their number of roles. As an example, participant quoted, "You have to satisfy both work and family lives that the less important role was displaced, not the most important". Furthermore, participants stated that the ability to priorities roles appears to be linked to individuals' values and aspirations and the varying importance they desired to the work and family roles.

\section{Work environment}

All the participants reported that the work culture highly affects their WLB. They mentioned that they had a teaching and learning environment, particularly compared to another job environment, it favors for their work satisfaction. Moreover, they explained when they got learning facilities they were involving work without stress and enjoy working. Therefore, a positive 
work environment helps to develop their career profession such as on time promotions, higher studies, being a quality researcher. They emphasized that an academic development is a great factor for satisfying both domains work and life.

Some of the interviewees reported that the predictability of the overall work schedule helps to reduce work life imbalance. That means their workload, work time, working days can be predicted it will not hinder their family responsibilities. They had some imbalance experiences because of highly unpredictable, both in terms of how many times they had to work, what tasks had to be complete, in workloads. Therefore, within the highly structured, predictable work schedules was a great chance for involving family roles.

\section{Personal Factors}

Participants highlighted that there are no similarities in the perceptions of the personal factors among individual towards WLB. However, different personal factors affect WLB in different degree of the number of women in the academic profession. Some mentioned receiving support from their family in the form of sharing of non-workloads (house chores) and understanding regarding their work commitments highly support to keeping the balance of both domains. The quoted responses, "I am happy to say that I share a lot of the household tasks, responsibilities with my husband and family members, I enjoy with working." According to interview results, receiving a great deal of support from family is the WLB. According to participants, with the effect of other factors, as an example, modernization of society or changing the traditional view, men helping more and more with household chores, but the weight of tradition is still heavy. Thus, many men do not perceive the idea of helping their spouses in household responsibilities. This cultural belief prevents women from balancing their lives at the workplace and at home.
Another highlighting fact of the participants, the ability to engage in a range of non-work activities (as hobbies), such as sports, reading, socializing and spending time with loved ones, the effect to reduces their work stress. More than half participants explained that they experienced severe stress or depression with a lack of leisure time because of involving more time in academic and other work duties. All most all participants reported that their experienced when they are involving work with less stress, work is intended to achieve personal goals if they financially strong and if they have a chance to service to society then they enjoy with working as women in this profession.

\section{Discussion}

Due to the lack of research in WLB, specially focusing on the higher education sector in the Sri Lankan context, this study was examined the WLB experiences among university lecturers. The aims of this study, namely to identify relationships between RDs of work and family and WLB among women academic staff in Sri Lankan Universities, and what factors they perceived as the contributing to support WLB behavior.

The results indicate that there is a negative relationship between RDs and WLB. This is in line with previous research findings by, Valcour (2007), Aycan (2008), Elisabeth, 2003, and Samsinar et al., (2010). It is evident that when individuals have a heavy workload and more responsibilities in their work and family roles it will be big challenged to attain their work and family satisfaction. In the previous literature, WLB often assists to be explained in term of work life conflict (Byron, 2005; Ford et al., 2007). When an individual's participating multiple roles such as work and life, inter-role conflict may arise. (Higgins, et al., 2010). Thus, work family balance means the absence of work life conflict or, work life conflict means work family imbalance. Therefore, through the 
related literature of work life conflict, the relationship between RDs and WLB can be identified. However, Carlson et al., (2013) highlighted that the absence of work life conflict is the historical definition of WLB.

Based on such considerations, researcher designed in this study RDs of work and WLB would have a negative relationship. The reason for that university lecturers' dedication to and enthusiasm for their job, because they have to build their academic career and fulfill professions goals (higher studies, research publications). Therefore, they might consider WD (heavy workload, working long hours) is a challenge contributing toward their overall WLB.

Noor (2004) has proposed that women are principal responsible person for the home yet, even if she is working. However, doing these responsibilities for family, it facilitates WLB and helps reduce work family conflict (Elisabeth, 2003). Huang et al. (2004) found that work family conflict has a positive correlation with the family demand for child care. This means WLB of individuals negatively correlated with family demands. Based on this argument, the research design in this study role demand of family and WLB would have a negative relationship. Similar to the previous result, the study was confirmed that there is a negative relationship between family demand and WLB. Sri Lankan culture compels women to be more responsible for the management of their homes, regardless of their profession. Though the women have to meet their WD, they take care of more domestic affairs in addition to their work roles with very little support from their spouses. This result indicates the importance of reducing working women's family responsibility and FDs for attaining WLB.

Current study's second objective was to identify the factors which contribute to supportive WLB behavior. Interpretation of interviews data produced the five themes central to supportive WLB as constructed by participants in this study; workplace flexibility, avoiding role interference, correct prioritization, good working environment and personal factors against the role demands. Different people achieve WLB differently and that WLB is a personal experience. However, the majority of participants described WLB in terms of flexibility of their work schedule and work time to much having more time for family demands. The literature study revealed that role conflict could include role interference. Regarding the direction of role interference, In the case of this specific profession, it was work interfering to life. Participant indicted that WLB issues are highly related to role interferences $(\mathrm{Lu}$ et al., 2006, Frone et al., 1997, Kossek et al., 2001).

Another individual issue that influenced WLB was the individual's ability to prioritise the roles. The findings also support prior research that found the inability to priorities one role over another might impact on work life conflict (Carlson et al., 1999). The findings from the study indicated that a supportive work environment, which means the environment with learning and researching culture support to achieve work satisfaction. Thus, work supporting environment tended to perceive a high-level WLB. Further individuals emphasized several personal factors which are directly influence their WLB, such as family support, having leisure time and engaging other activities. Finally, the study was found to be valuable by participants, in that it increased their self-awareness about WLB and as such lead to the producer of alternative solutions to overcome the challenges faced in integrating their multiple roles of work and life.

\section{Limitations}

The current study focuses WLB among women lectures in Sri Lankan state universities. It offers valuable insights on 
how to attain WLB for women in the academic profession. While valuable information has been generated from the study, it is noted that the study focused only the state universities in the higher education sector in Sri Lanka.

\section{Further Studies}

This study investigated the RDs of work and family and WLB, based on women in the academic profession. Further, it is better to investigate WLB experience of other professions in other sectors. Although this study provides an original contribution to the existing literature, the researcher expects that these findings encourage further research and applications how women employees attain a better WLB. This study specifically related to women employees. Recent literature argued that men also facing the problem of work life imbalance and work life conflict. Therefore, it needs to encourage the research in this area focusing men and both genders, it may lead to valuable findings of the multiple role demands of work- life and WLB.

\section{Conclusion}

The present study explores the problem associated with WLB and RDs of women in the teaching profession in Sri Lanka, by using mixed methodology. Although WLB has a rich literature, with most empirical studies in this area have been conducted in the Western context.
The present study examined the identified relationships between role demands and WLB, empirically with the Sri Lankan context. The explanatory phase of this study results revealed, work demand shows a negative significant relationship with WLB. Similarly, family demands also show a negative significant relationship with WLB. The other phase of the study which is exploratory in nature, aim to find out supportive factors for increasing WLB. Findings from exploratory part of the study, particularly the five main recommendations (factors supportive to WLB behavior) made by 20 interviewees (workplace flexibility, avoiding role interference, correct prioritization, good working environment and personal factors against the role demands), may be used by women university lecturers in hope to improve their WLB.

The researcher believes that this mixed method study provides empirical evidence to understand the relationships between role demands and WLB and, how to improve WLB when with the high demand for both domains of work and family. Finally, this study sends an important message to individuals to encourage work and family satisfaction. 
Welmilla I., KJM, 2018, 7 (2)

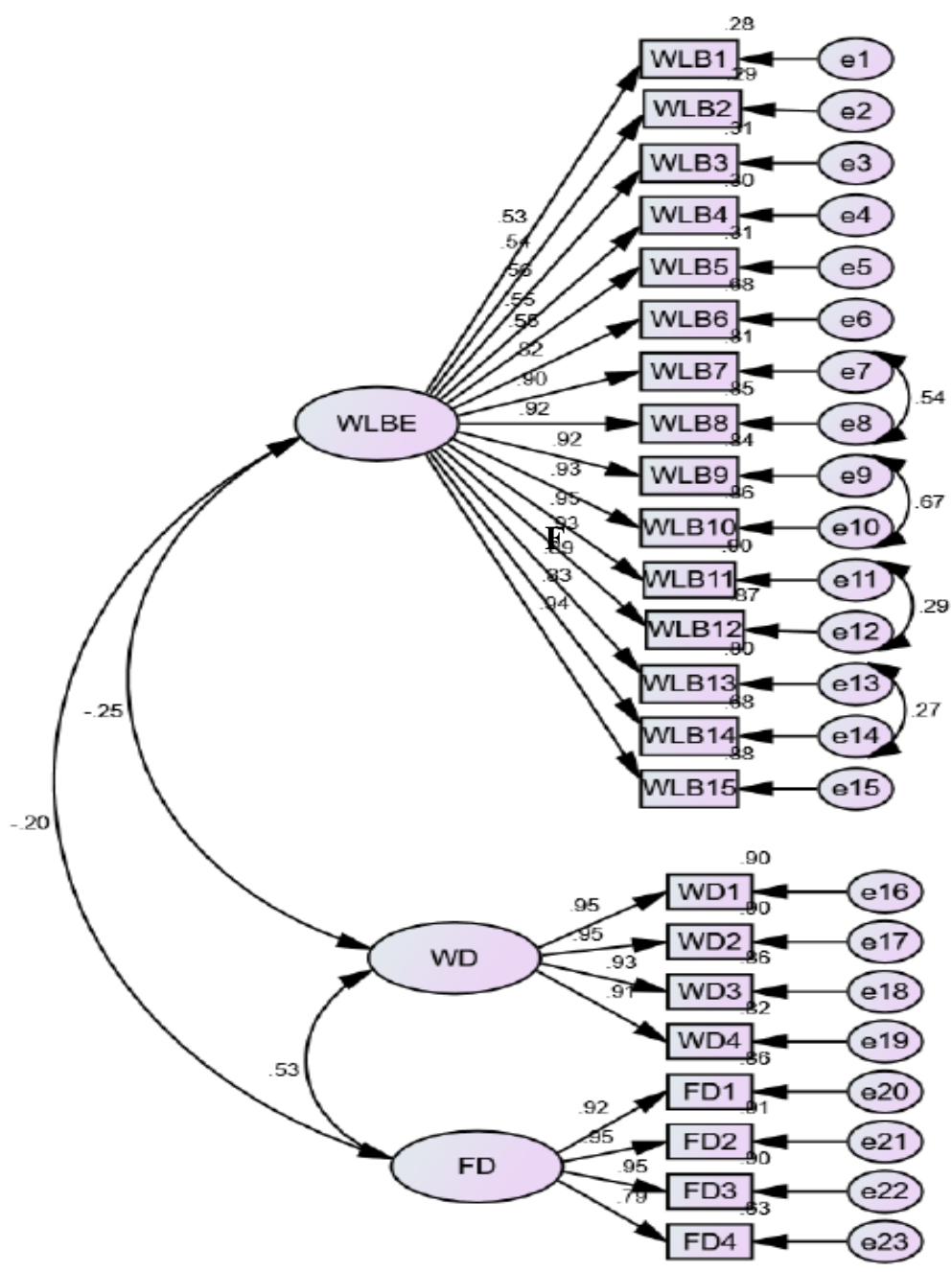

Figure 2: The Modified full Measurement Model

Source: Results of AMOS graphics, 2018 


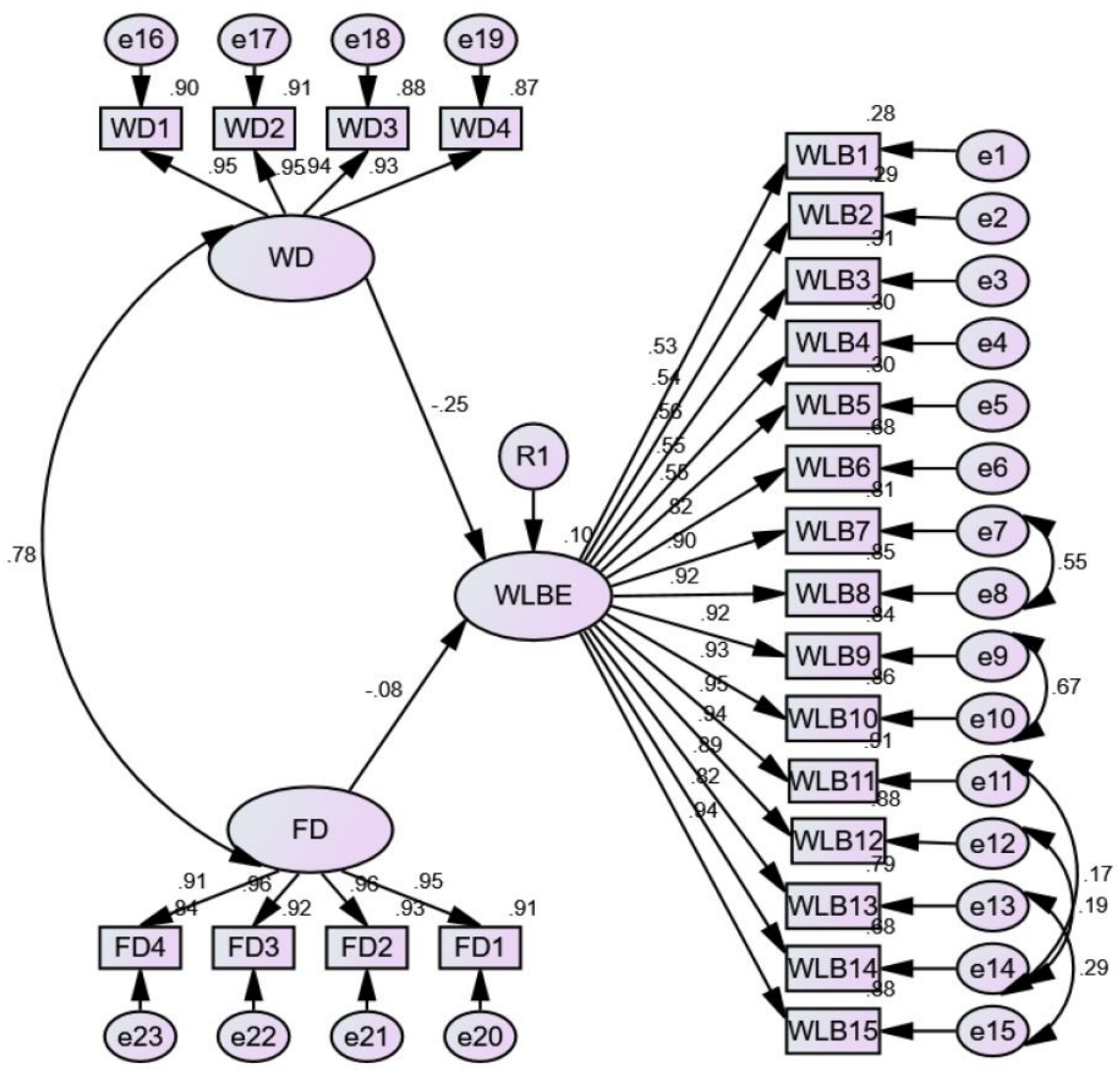

Figure 3: Results of the Structural Equation Model

Source: Results of AMOS graphics, 2018

\section{References}

Allen, T.D, Johnson, R.C.,Kiburz, K.M. \& Shockley, K.M. (2013). Work - Family Conflict: A Review and Agenda for Future Research. Journal of Personnel Psychology,66(02), 345-376.

Aycan, Z. (2008). Cross-cultural perspectives to work- family conflict. Handbook of work- family conflict (pp.359-371). Cambridge University press, Cambridge.

Batt, R. \& Valcour, P.M. (2003). Human resource practices as predictors of workfamily outcomes and employee turnover. Industrial Relations, 42 (02),189-220.

Blunsdon, B., Blyton, P., Reed, K., \& Dastmalchian, A. (2006). International perspectives on the balancing of multiple roles. Work Life Integration, Macmillan: UK. 
Boyar, S.L., Carr, J.C., Mosley, D.C., \& Carson, C.M. (2007). The development and validation of scores on perceived work and family demand scales. Educational and Psycholohical Measurement,67,100-115.

Byron, K. (2005). A meta- analytical review of work-family conflict and its antecedents. Journal of Vocational Behaviour, 67(02), 169-198.

Carlson, D.S. \& Perrew, P.L. (1999). The role social support in the stressor- strain relationship: an examination of workfamily conflict. Journal of Management, 25 (04), 513-540.

Carlson, S.D., Kacmar, M.K., Grzywacz, G.J., Tepper, B., \& Whitten, D. (2013). Work- family balance and supervisor appraised citizenship behavior: the link of positive affect. Journal of Behaviour \& Applied Management, 14(02), 87-106.

Chan, D.K.K. (2008). Revisiting Post-colonial Education Development: Reflections on Some Critical Issues. Comparative Education Bulletin: Special Issue, Education and Development in Post-Colonial Societies, 11, 21-36.

Chandra, G. (2017). Improving the quality of university education in Sri Lanka: an analysis of Quality Assurance Agency Council's reviews. Sri Lanka Journal of Social Sciences, 40(1)03-15. DOI:http://dx.doi.org/10.4038/sljss.v40i1 .7497

Clark, S. (2001). Work cultures and work/ family balance. Journal of Vocational Behaviour, 58 (03), 348-365.

Cohen, A., \& Kirchmeyer, C. (2005). The cross- cultural study of the work/ nonwork interface among Israeli nurses. Applied Psychology: An International Review,54 (02) 40-121.
Diaco, E., Hughes, A., \& McKelvey, M. (2012). Universities as strategic actors in the Knowledge Economy. Cambridge Journal of Economics, 36, 525-541 DOI: https://doi.org/10.1093/cje/bes024 pp.385-417

Edura, W., Mohamad, S.N., Azura, O., \& Izhairi, I. (2012). Work/Family Conflict: The Link between Self-Esteem and Satisfaction Outcomes. Social and behavioral Science, 65,564-569, https://doi.org/10.1016/j.sbspro.2012.11. 166.

Elisabeth, G. (2003). Women doctors in Norway: The challenging balance between career and family life. Social Sciences \& Medicine Journal, 57 (07), 13271341, DOI: $\quad 10.1016 / \mathrm{S} 0277-$ 9536(02)00513-0

Fisher-Mccauley, G., Stanton, J., Jolton, J., \& Gavin, J. (2003). Modelling the relationship between work-life balance and organizational outcomes. paper presented at Annual Conference of the Society for Industrial- organizational Psychology, Orlando, FT.

Flores, M. A., \& Day, C. (2006). Contexts which shape and reshape new teachers' identities: A multi-perspective study. Teaching and Teacher Education, 22(2), 219-232.

Ford, M.T., Heinen, B. A., \& Labgkamer, K.L. (2007). Work and family satisfaction and conflict: a meta- analysis of cross-domain relations", Journal of Applied Psychology, 92 (01), 57-80. Doi: 10.1037/0021-9010.92.1.57.

Frone, M.F. (2003). Work family balance. In. JC Quick \& L.E. Tetrick (Eds), Hand book of Occupational Health Psychology (pp.143-162). Washington. APA. 
Frone, M.R., Russel, M. \& Cooper, M.L. (1997), Antecedents and outcomes of work- family conflict: testing a model of the work- family interface. Journal of Applied Psychology, 77 (01), 65-75.

Goyal, M. \& Arora, S. (2012). Harnessing work: family life balance among teachers in educational institute. International Journal of Applied Services marketing Perspectives, 1 (02), 170-176.

Greenblatt, E. (2002). Work-life balance wisdom of whining? Organizational Dynamics, 31(02),177-193.

Hair, J. F., Black, W. C., Babin, B. J., \& Anderson, R. E. (2010). Multivariate data analysis: A global perspective ( $7^{\text {th }}$ ed.). Upper Saddle River, N.J: Pearson Education.

Henseler, J., Ringle, C., \& Sinkovics, R. (2009). The use of partial least squares path modelling in international marketing. Advanced in International marketing, 20(01), 277-320.

Higgins, C. A., Duxbury, L.E., \& Lyons, S. (2010). Coping with overload and stress: men and women in dual -earner families. Journal of marriage and Family, 72( 04), 847-859.

Higgins, C., Duxbury, L., \& johnson, K.L. (2000). Part- time work for women: does it really help balance work and family? Human Resource Management, 39 (1),1732.

Hill, E. (2005). Work-family Facilitation and Conflict: working fathers and mothers work-family stressors and support. Journal of Family Issues, 26, 793- 819.

Huang, Y.H., Hammer, L.B., Neal, M.B., \& Perrin, N.A. (2004), The relationship between work-to-family conflict and family-to-work conflict: a longitudinal study,
Journal of Family and Economic, 25, 79100.

Kossek, E.E., Baltes, B.B., \& Matthewa, R.A. (2011). How work- family research can finally have an impact in organizations. Industrial and Organizational Psychology, 4(3), 352-369.

Lu, L., Gilmour, R., Kao, S.F., and Huang, M. T. (2006). A Cross-Cultural Study of Work/Family demands, Work/Family Conflict and Wellbeing: the Taiwanese vs British, Career Development International, 11(1): 9-27.

Major, V.S., Klein, K.J. and Ehrhart, M.G. (2002). Work time, work interference with family and psychological distress. Journal of Applied Psychology,08(3), 427-436.

Noor, N.M. (2004). Work family conflict, work and family role salience, and women's well-being. The Journal of Social Psychology, 144(4), 389-405.

Poelmans, S., Spector, P.E., Cooper, C.L., Allen, T.D., O'Driscoll, M., \& Sanches, J.I. (2003). A cross national comparative study work /family demands and resources. International Journal of CrossCultural Management, 3(3), 275-288.

Punia, V. \& Kamboj, M. (2013). Quality of work-life balance among teachers in higher education Institutions. Learning Community,4(3), 197-208.

Roehling, P.V., Jarvis, L.H, \& Swope, H.E. (2005). Variation negative work family spillover among White, Black and Hispanic American Men and Women: Does ethnicity matter? Journal of Family Issues, 26(6), 840-865.

Samsinar, S.M., Murali, S. \& zhairi, I. (2010). Relationship between work-family conflict and quality of life: An investigation into the role of social support. Journal of Managerial Psychology, 25(1), 5881 , 
Welmilla I., KJM, 2018, 7 (2)

http://org/doi/10.1108/026839410110138

$\underline{76}$

Voydanoff, P. (2005). Toward a conceptu-

Valcour, M. (2007). Work-based realization of perceived work- family fit and sources as moderators of the relationship between work hours and satisfaction with work-family balance. Journal of Applied Psychology, 92(6), 1512-1523. balance: a demands and resources approach. Journal of Marriage and Family, 67(4), 822-836. 